\title{
Exploring the Intelligent and Collaborative control for E-Government System
}

\author{
Fangli Su ${ }^{1}$, and Hongtao $\mathrm{Zhu}^{2}$ \\ I Zheng Zhou Institute of Aeronautical Industry Management, Zheng Zhou \\ 450015, P.R.of China \\ Suli_2000@163.com \\ 2 Zheng Zhou Institute of Aeronautical Industry Management, Zheng Zhou \\ 450015, P.R.of China \\ pds_zhht@126.com
}

\begin{abstract}
This article embarked from the e-government affairs and the collaboration theory, has discussed the meaning of intelligent and collaborative control for E-government system, and proposed the intelligent and collaborative E-government system.
\end{abstract}

\section{Introduction}

The important feature of the network era is society and government's informationization, the main content of government's informationization is the implementation of e-government affairs, it has changed the official organization pattern and the government forms, and then has changed the government's management model. From the late 20th century to present, the human society has entered the information time, corresponding to the form of government is network government. organization is a complex system, the interaction between elements of the system has the driving force of innovation. the non-linear interaction of various essential factors in complex system interior is the inner impetus impelling the system to the order development. The collaboration effect is the interaction between various subsystems in the complex system, producing the effect beyond their effects alone, also is a whole greater than the sum of its parts.

\subsection{E-government}

Several recent investigations $[2,3,5]$ indicate , E-government is the process of offering better government service to the public at a lower cost, improving the 
decision-making and investment environment, migrating the government's management, service, and the communication function to the internet. E-government is the means to modernize public administration and to achieve social participation. Among them, "electronic" is a method, and "the government affair" is the key. Egovernment has to do more with "government" than with the "e."

\subsection{Collaboration theory}

The synergetic was proposed in the sixties of the twentieth century by Germany's Professor Hermann Haken, which studies the rules of interaction between systems. It has been shown [1] that it contains two basic viewpoints:

\subsubsection{Coordination effect}

In complex systems, it exists the non-linear mutual function between various essential factors, when the outside control parameter achieved a certain value, the elements are interrelated, interconnected, replacing their relative independence, thus displays the coordination, cooperation, enhancing their overall effect, and the system moves towards the ordered state from the disordered state.

\subsubsection{Self-organizing}

Self-organization is a structure, forming through the systems' internal drive, which emphasizes achieving the coordination effect of a complex system. The formation of self-organizing system requires four conditions: The system must be open and be able to exchange material, energy, and information with the environment; the external function, through its internal mechanism to be effective; the non-linear interaction of elements within the system; Fluctuations as the catalyst. If the four conditions are met, the system will form self-organization in the absence of external directives.

\section{2 the meaning of intelligent and collaborative control for $E$ - government system}

\subsection{The transformation from information management to knowledge management.}

The e-government affairs in our country has entered the third generation, its main goal is enhancing the government's decision-making ability by using knowledge management technology under government information environment, establishing Network-based distributed government structure, and providing trans-departmental government service through distributed "one-stop" service center. This stage of egovernment affairs has not been limited in the information management or transaction processing, but to enhance the government departments' ability about knowledge collection, analysis, transmission and use, to integrate knowledge 
management closely with business processes, thus to enhanced the whole management level and efficiency of government.

\section{2 personalization of E-service}

In the public service, in view of the government offices are located in different locations, thus the office organization is dispersible, and the service window is multitudinous. Even for a simple business, need all the relevant agencies and department. The integrated use of various departments' public information resource is limited, difficult to play the best efficiency of automatic system. So it is emphasized that the government website must face the different types of user groups to provide the entire life information and the service and the integrated service resources.

\section{3 performance optimization of collaborative system}

The future collaborative information system will be more agile and real-time, manifesting the people-centered thinking, adapting to the government affairs' transformation from management to service. Through applications, processes and information departments of synergy, Collaborative government affairs greater play to the advantages. The collaborative government affairs are not only a better tool to do the similar matter, but also is a set tools which can handle the different or better matters, it is one brand-new way to provide services. The collaborative government affairs emphasize taking government staff's cooperation as the core, strengthening government information resource's sharing, optimizing the work flow, is the highest stage of current e-government affairs technology's application.

\subsection{Deeply development of e-government application}

With the development of e-government, application level has also been constantly rising. Some government departments' network which was completed at the early times began to expose some problems. First, as the government departments have their own original internal network, how can these heterogeneous network be interconnected is still a problem; Secondly, after the network linked, how can consolidate network resources, make full use of the department's original data; finally, how to protect the internal network resources. These problems have solutions now: Establishment of Intelligent and Collaborative e-government system.

\section{Collaborative and intelligent e-government system}

E-government need to satisfy government departments more in-depth application requirements, System should not always stay in the conventional business and business management, but shift to operational synergies and collaborative decision making. 
E-government has pushed for a collaborative management model. It has been shown [4] that Collaborative management includes three aspects: First, the vertical separation of powers within the government collaborative management; Second, the government horizontal integration synergies; Third, the government and other manager's collaborative management.

The actual demand of government department, forced the building of egovernment to the collaborative and intelligent direction. The so-called government intelligence is, to improve the effectiveness and coordination of transaction processing as well as the scientific and continuity of significant decision-making, a information system that constructed by using the information technology to be used for coordinating service and decision-making between the departments, namely government intelligent system.

\subsection{The core content of government collaborative and intelligent system}

Electron government collaborative and intelligent system is studied on the basis of collaborative theory, auto-adapted websites, and data mining. The basic technical construction is shown in figure 1.

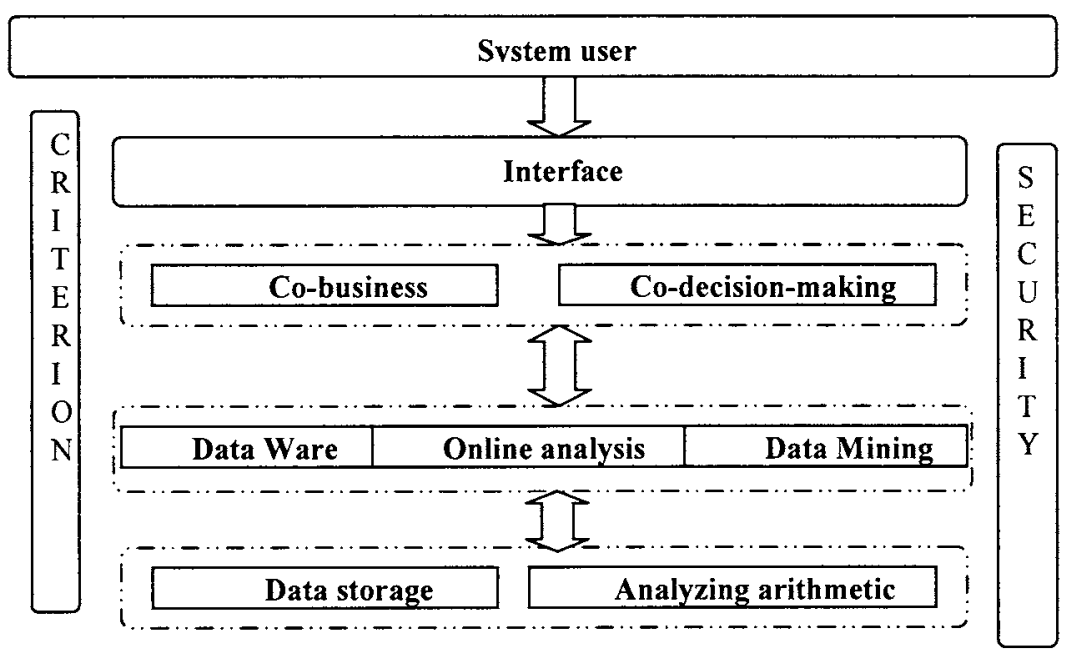

\section{Comnuter network +operating svstem}

Fig. 1 The technical construction of government collaborative and intelligent system

Synthesizing its ideological sources, technical basis, existing tools and so on, the core content of the intelligent and collaborative government may approximately divide into following five aspects: 1) Data processing based on network communications, the data originates from many government departments, the use of network communication will enable information collection, transmission and digital storage more real-time; 2) Business collaboration Based on the message mechanism, 
the major goal to establish the intelligent and collaborative government system is strengthening the government departments with coordination; it should be clear about the single department work standard, and the basic principle which should be followed on exchanging and sharing information. Technically, based on the data exchange service coordination, the application integration or the flow coordination, they are using the system's message mechanism to trigger event, thus completing coordination mission. 3) The information management based on the subject analysis, the intelligent and collaborative government system is not merely technical, but also unceasingly establishes the business-oriented analysis subject. 4) Auxiliary decisionmaking based on the knowledge discovery. The auxiliary decision-making function of the intelligent and collaborative government system is to carry on the decisionmaking judgment using the new knowledge. 5) Administrative management based on the evaluation of the performance, the intelligent and collaborative government system should be able to evaluate the government's administrative capacity and performance. it is helpful to establish the reasonable drive mechanism.

\subsection{Collaborative and Intelligent e-government model}

\subsubsection{Personalized and custom-made information services of the e-government system}

As a public information service system, the problem that E-government needs urgently to solve is how to ease the strong contradictions caused by the contrast between the massive administrative information and the information control ability of users. in order to satisfy the users' usability requirements to the e-government system, what the personalized and custom-made information service present to users should be user-friendly and includes the information which the user be interest in.

In view of the above, proposes such a design concept: By analyzing the activities of users, the system automatically collects related information, transmits this information to user's desk promptly and regularly, helps users identify valuable information resources. This is a dynamic process; it can auto-adapted to user's interest and the change of information source.

Assume that add such a module to the e-government system, may be called the subject intelligence briefcase which based on personalized and custom-made information service. The module can automatically record each user's characteristics and establish the knowledge system, have good self-adaptive, learning and customized characteristics; According to the characteristics of users to filter the retrieved information, and push useful information to users, enable users to access their really wanted information accurately, direct and effectively. Its service model is shown in figure 2 . 


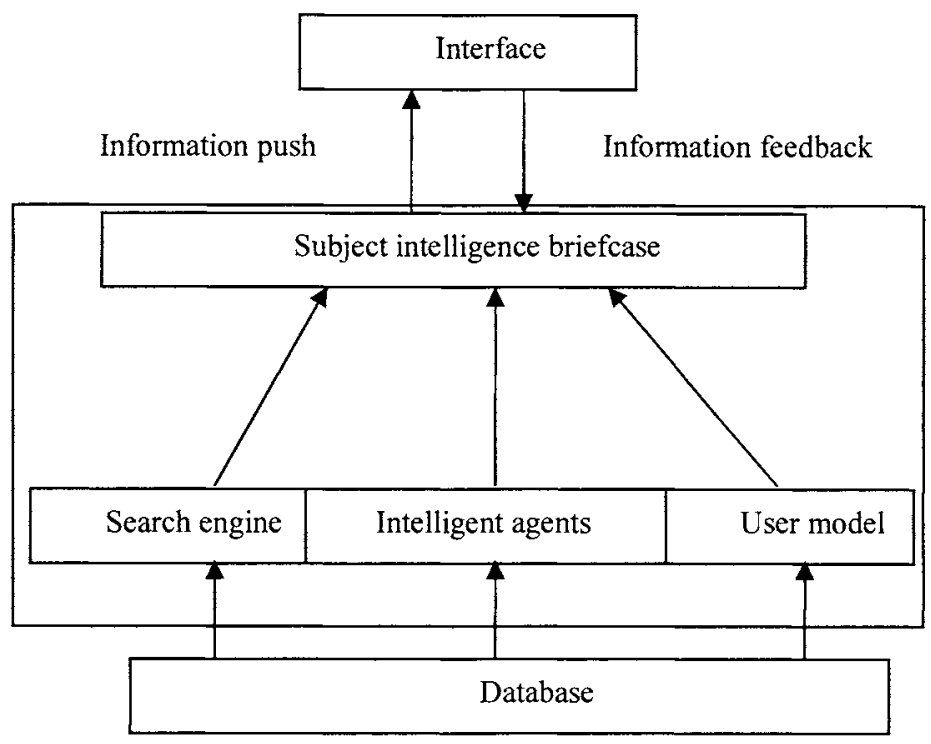

Fig. 2. The subject intelligence briefcase service model

\subsubsection{Electronic documents intelligent retrieves of E-government system}

Document includes the various information used in e-government, is an important component of e-government. How to find out the documentation which related to existing work from the rich e-government documents is an important task of egovernment document intelligent retrieval. Several recent investigations $[6,7]$ indicate, in view of the lack of semantic retrieval, we can use the semantic egovernment document retrieval. Combining the resources tagging of semantic web, according to the existing classification system and thesaurus in e-government, carries on the knowledge inference and the intelligent retrieval under the semantic net frame, enhances the accuracy of retrieval.

\subsubsection{Intelligent network invasion examination of e-government system}

The invasion examination technology is using the trace of the intruder, like the defeated records of attempting to land and so on, so can discover the illegal invasions which come from the external or internal. it takes survey and control as the technical essence, and Play a proactive role in the defense. In the invasion examination the functional technology includes: method based on neural network; method based on expert system; method based on model inference.

(1) Intrusion detection method based on neural network: This method has the study and auto-adapted function to the user behavior; it can process effectively according to the information of actual examination, and make judgment of possible invasion.

(2) Intrusion detection method based on expert system: according to the experience from analyzing suspicious behavior by the security expert, forms a set of 
inference rules; and then establishes the expert system, so this expert system can automatically analyzes the behavior of invasion.

(3) Intrusion detection method based on model inference: According to the characteristics of certain behavior that executed by intruder, to establish an invasion behavior model, and according to this behavior model to judge whether user's operation belongs to intrusions.

\section{4 conclusion}

The network era need the collaborative management mode for government, and the E-government sped up the pace. With the increasing depth of e-government, the intelligent and collaborative government will be the future direction. In practical application we should strengthen the affairs management and information communication at administrative departments, pay attention to their professional background knowledge and work experience of the personnel. The application of intelligent and collaborative e-government needs some analysis software to support, but cannot excessively rely on the software tools. E-government has to do more with government than with the $\mathrm{e}$.At the same time, the construction and execution of Openness in government affairs, exchange of information system is the fundamental guarantee to the service coordination.

\section{References:}

1. S. J. Han, S. Y. Nie, and W.Y. Zhao Remote-cooperative official business system design,Journal of Dalian Institute of Light Industry.(2), 149-151(2006).

2. Z.T, Yuan Q.Y, Zhang X, Wang and Y, Yang Research of CWE and its application in E-government,Computer Engineering and Design.(15), $2892-$ 2894(2006)

3. W. Chen, G.Z. Yang Land L Chen S.M., IU Research of E-government Workflow Model Based Message Oriented Midelle Ware,Science Technology and Engineer.(14), 1021-1025(2005)

4. B. Xu -X.,Jia -B. Zhan, and Y. Liu - wen, Research on the Applying Patterns of Workflow Technology in Coordination of $\mathrm{E}$ - government Business, Information Science, (5), 742-745(2005)

5. J.Zhang 1, and KJ. Hu.,Study on Electronic Government Cooperation Work Model Based on Cooperative Unit,Journal of Tongii University,(10), 1380-1384(2005)

6. F. Yang, and Z.S. Yang, E-Government document retrieval based on semantic Web,Computer Applications, (10), 2434-2436(2005)

7. Z.J Zhang, H.L Liu.,and J. Sun,Study on thematic and intelligent portfolio service in E-government system,Journal of Northeast Normal University (Natural Science Edition), (4), 38-42(2005) 